\title{
STRUCTURAL, DIELECTRIC AND ELECTRICAL PROPERTIES OF ZIRCONIUM DOPED BARIUM TITANATE PEROVSKITE
}

\author{
SHAMIMA CHOUDHURY*, SHURAYYA AKTER \\ Department of Physics, University of Dhaka, Dhaka-1000, Bangladesh
}

M. J. RAHMAN, A. H. BHUIYAN

Department of Physics, Bangladesh University of Engineering and Technology

Dhaka-1000, Bangladesh

S. N. RAHMAN, N. KHATUN, and M. T. HOSSAIN

Industrial Physics Division, Bangladesh Council of Scientific and Industrial Research, Dhaka-1205, Bangladesh

\begin{abstract}
The microstructural and electrical properties of pure and Zirconium $(\mathrm{Zr})$ doped Barium titanate (BT) samples with general formula $\mathrm{Ba}\left(\mathrm{Ti}_{1-\mathrm{x}} \mathrm{Zr}_{\mathrm{x}}\right) \mathrm{O}_{3}$ (where $\mathrm{x}=0.0,0.1,0.2$ and 0.3 ), prepared by high temperature solid state reaction at a sintering temperature of $1250^{\circ} \mathrm{C}$, were investigated. Dielectric and structural properties of BT ceramics is influenced significantly by small addition of $\mathrm{ZrO}_{2}$. Scanning Electron Microscope (SEM) observations revealed enhanced microstructural uniformity and retarded grain growth with increasing $\mathrm{Zr}$ content. The dielectric study with frequency at room temperature in the frequency range $75 \mathrm{kHz}$ to $30 \mathrm{MHz}$ shows that dielectric constant decreases with increasing frequency. The resistivity of the samples shows asymptotic behavior with the variation of frequency and was found to be of the order of $\sim 10^{3} \Omega$-m. Loss factor of the grown materials decreased with increasing frequency but it became independent at higher frequency range.
\end{abstract}

\section{INTRODUCTION}

The perovskite ceramics family includes many titanates and is used in various electro-ceramic applications, for example, electronic, electro-optical, and electromechanical applications. Barium titanate (BT) perovskite structure is a common ferroelectric material with a high dielectric constant, widely utilized to manufacture electronic components such as multilayer capacitors, positive temperature coefficient thermistors, piezoelectric transducers, and a variety of electro-optic devices ${ }^{(1)}$. The high dielectric constant of BT makes it an especially desirable material is the fact that its electrical properties can be controlled within a wide range by means of mixed crystal formation and doping. Electrolytic capacitors are the first to be considered when large blocks of capacitance are needed in electrical circuits. Other capacitors offer such a large capacitance per unit volume at a low cost. Electrolytic capacitors are deservedly popular in bypass, blocking and power supply filter applications and for motor starting purpose ${ }^{(2)}$. BT powder is usually mixed with various types of additives in order to obtain better performances and a good control over grain size and electrical characteristics of ceramics. It has been found that the dielectric properties of polycrystalline BT depend to a great extent on the grain growth during sintering and on additive type and concentration ${ }^{(3)}$. Additives which change the microstructure can also modify the dielectric properties of BT ceramics. Studies on the effect of Zr addition to BT show that the Zr addition shifted

* Author to whom correspondence may be made. 
the Curie point and depressed the dielectric peak. $\mathrm{Zr}^{4+}$ can substitute for $\mathrm{Ti}^{4+}$ ions as isovalent doping. Addition of zirconia particles into barium titanate can form a core-shell structure. The desired temperature-stability in dielectric properties is achieved by formation of core-shell grains ${ }^{(4)}$. Ceramic multilayer capacitors based on BT can be chemically or physically modified to exhibit temperature-stable dielectric behavior (less than $\pm 15 \%$ deviation ), over the temperature range -55 to $125{ }^{\circ} \mathrm{C}$. The stability can either result from chemical substitution in the ceramic, from a small-grained microstructure, or from the presence of core-shell grains ${ }^{(2)}$.

Many investigations on the material belong to the perovskite family $\mathrm{ABO}_{3}$. It is reported that homovalent or heterovalent substitutions of barium or titanium ions lead to remarkable changes in various characteristics ${ }^{(4,5,6)}$. Many researchers have shown their interest in the solid solution system $\mathrm{Ba}\left(\mathrm{Ti}_{1-\mathrm{x}} \mathrm{Zr}_{\mathrm{x}}\right) \mathrm{O}_{3}$ with different concentrations of $\mathrm{Ti}$ and $\mathrm{Zr}$. It has been reported that the $\mathrm{Zr}$ substitution in BT affects the transition temperatures. The three transition temperature of BT (rhombohedral to orthorhombic, orthorhombic to tetragonal, and tetragonal to cubic) move closer with initial increase of $\mathrm{Zr}$ content, and merge near room temperature for $\mathrm{Zr}>15$ at.\% ${ }^{(7,8)}$. It is also reported that the solid solution $\mathrm{Ba}\left(\mathrm{Ti}_{1-\mathrm{x}} \mathrm{Zr}_{\mathrm{x}}\right) \mathrm{O}_{3}$ does not exist for $\mathrm{x}>0.42$, and beyond this limit the two phase $\mathrm{BT}$ and $\mathrm{BaZrO}_{3}$ are separated. This inspired us to study the structural and dielectric properties of solid solution composition $\left[\mathrm{Ba}\left(\mathrm{Ti}_{1-\mathrm{x}} \mathrm{Zr}_{\mathrm{x}}\right) \mathrm{O}_{3}\right]$ where $\mathrm{x}=0.0,0.1,0.2$ and 0.3. The dielectric properties were investigated as a function of frequency in the range of 75 $\mathrm{kHz}$ to $30 \mathrm{MHz}$.

\section{EXPERIMENTAL PROCEDURE}

The materials used in the preparation of $\left[\mathrm{Ba}\left(\mathrm{Ti}_{1-\mathrm{x}} \mathrm{Zr}_{\mathrm{x}}\right) \mathrm{O}_{3}\right]$ samples with $\mathrm{x}=0.0,0.1$, 0.2 and 0.3 , were Barium oxide $(\mathrm{BaO})$, Titanium dioxide $\left(\mathrm{TiO}_{2}\right)$, and Zirconium oxide $\left(\mathrm{ZrO}_{2}\right)$. All the materials were procured from the local market. The purity of chemicals was of analytical grade as stated by the manufacturer. $\mathrm{BaO}$ and $\mathrm{TiO}_{2}$ were used as parent materials and $\mathrm{ZrO}_{2}$ as an additive. Appropriate amount of starting materials was thoroughly mixed, dried, grounded and then calcined at $900{ }^{\circ} \mathrm{C}$ for three hours and then pellets were formed. The pellets were then sintered at $1250{ }^{\circ} \mathrm{C}$ for four hours and their dielectric constant was calculated measuring the capacitance.

TYPE-ROS 3/20, FNR 7601905, HOCHST TEMPERETURE 1500, GERMANY was used for sintering and HP 4230 Precision LCR meter was used for measuring Capacitance (C), Resistance (R) and Dissipation Factor (D) in the frequency range from $75 \mathrm{kHz}$ to $30 \mathrm{MHz}$.

The surface morphology and microstructures of the obtained ceramic samples were characterized by a Hitachi S-3400N Variable Pressure Scanning Electron Microscope (SEM) equipped with an EDAX system. Microstructure evaluations were made from as-sintered surface of the sample. The evolution of particle size of the BT ceramics after $\mathrm{Zr}$ doping, were monitored by SEM-image analysis and EDAX.

\section{RESULTS AND DISCUSSION}

(i). Microstructure Characteristics: The effects of $\mathrm{ZrO}_{2}$ addition to BT structure are compared in the SEM micrographs of as-sintered surfaces for samples sintered at $1250^{\circ} \mathrm{C} / 4 \mathrm{~h}$ in Fig. 1 . The microstructure of BT ceramic doped with $\mathrm{ZrO}_{2}$ at different concentrations exhibited homogenous grain size distribution. Dielectric properties and structural characteristics of BT ceramics were significantly influenced by the small 
The effects of $\mathrm{ZrO}_{2}$ addition to BT showed that a dense microstructure consisting essentially of small grains (average grain size $\sim 1.238 \mu \mathrm{m}$ ) was observed for pure BT. After doping $5.18 \mathrm{wt} \% \mathrm{ZrO}_{2}$ in sample 2, grain size increased significantly (average grain size $\sim 4.158 \mu \mathrm{m}$ ) as shown in Figure 1(b). In contrast, with the increase of doping weight of $\mathrm{ZrO}_{2}$, samples grain size decreased as listed in Table 1. All $\mathrm{Zr}$ doped BT grains had nearly hexagonal shape as shown in Figure 1. With the increase in $\mathrm{Zr}$ concentration the fraction of large grains decreased significantly, resulting in bimodal distribution of large grains in the fine grain matrix ${ }^{(9)}$.

Timothy R. Armstrong and Relva C. Buchanan ${ }^{(2)}$ showed that grain structure of the sintered Zr doped BT contains two regions, the core and the surrounding shell. In general, the core is the undoped region with ferroelectric domains and the shell is the highly doped region. Higher sintering temperature and/or longer sintering times promote a more homogeneous distribution of additives that eventually cause the core-shell structure to disappear.

(ii). EDAX Spectra: The EDAX detector measures the number of emitted X-rays versus their energy. The energy of the X-ray is characteristic of the element from which the Xray was emitted. A spectrum of the energy versus relative counts of the detected X-rays is obtained and evaluated for qualitative and quantitative determinations of the elements present in the sample volume.

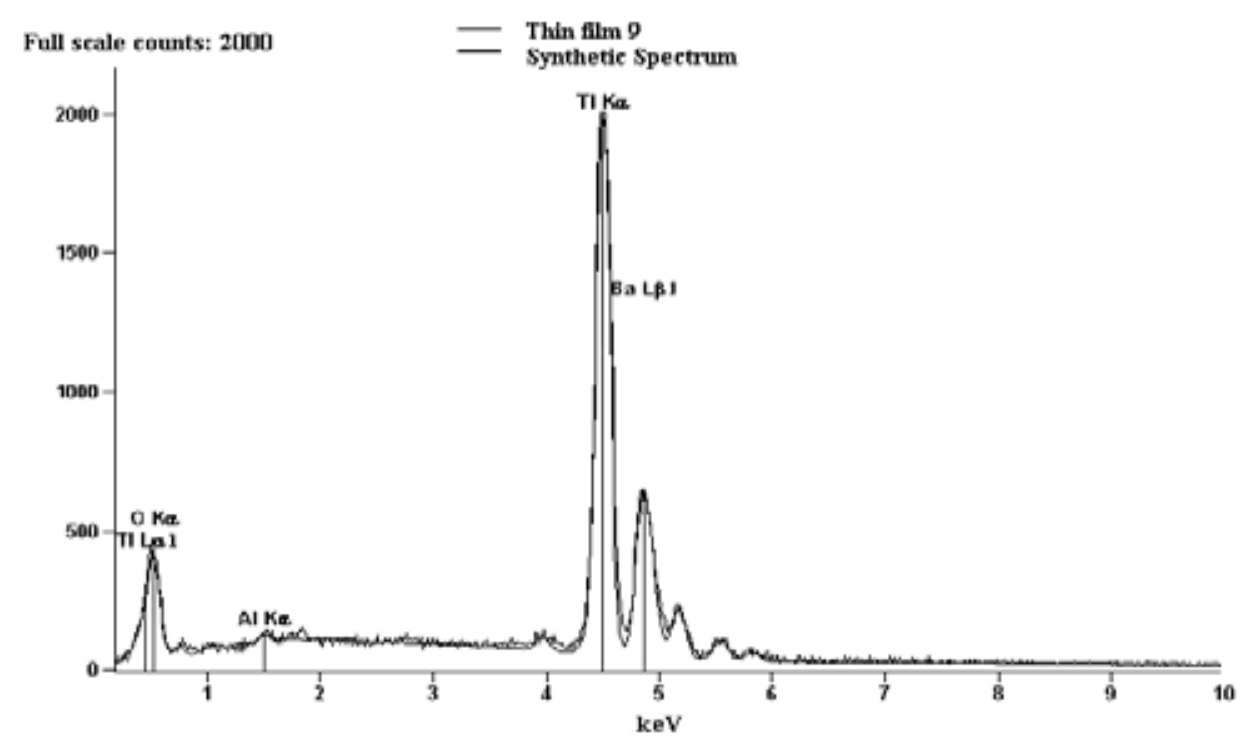

Fig 2: EDAX Spectrum for pure BT 
samples. By adding oxide group softeners, hardeners and stabilizers these materials can be modified. Softeners (donors) reduce the coercive field strength, elastic modulus and the aging effects and increase the dielectric constant and mechanical losses. Doping by hardeners (acceptors) gives higher conductivity, reduces dielectric constant and increases mechanical quality factor and aging effect ${ }^{(11)}$.

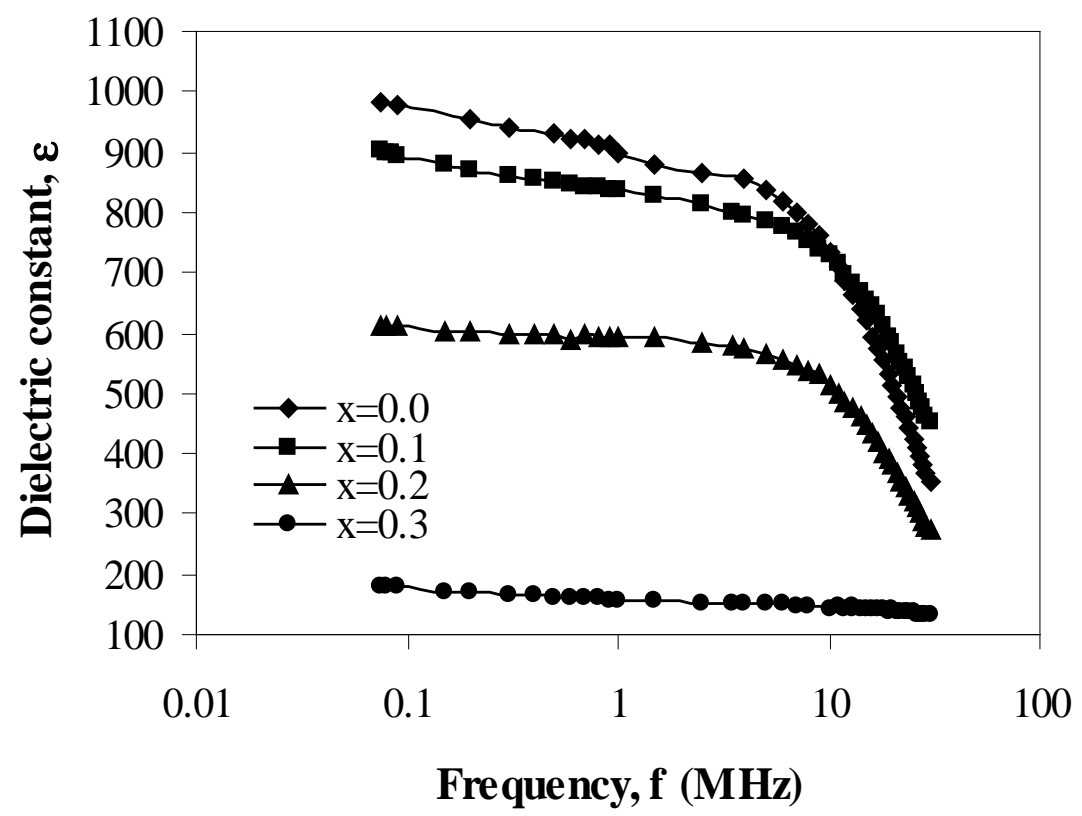

Fig. 4: Change of dielectric constant with frequency of $\mathrm{Ba}\left(\mathrm{Ti}_{1-\mathrm{x}} \mathrm{Zr}_{\mathrm{x}}\right) \mathrm{O}_{3}$ with $\mathrm{x}=0.0,0.1,0.2$ and 0.3$)$

Dielectric constant of pure BT bulk samples showed a maximum value of about 1000 when grain size was around 1.238 $\mu$ m.Dielectric constant decreased for doped samples. For sample 2 [ $\mathrm{x}=0.1$ ] grain size $(4.158 \mu \mathrm{m})$ was increased but its dielectric constant behavior was similar to pure BT (grain size 1.2376 $\mu \mathrm{m}$ ) with frequency. On the other hand for sample-3 (grain size 2.113 $\mu \mathrm{m}$ ) and sample-4 (grain size 1.538 $\mu \mathrm{m}$ ) dielectric constant decreased significantly. After $5.18 \mathrm{wt} \% \mathrm{ZrO}_{2}$ doping, grain size of the grown materials increases and for further increase of $\mathrm{ZrO}_{2}$ in $\mathrm{Ba}\left(\mathrm{Ti}_{1-\mathrm{x}} \mathrm{Zr}_{\mathrm{x}}\right) \mathrm{O}_{3}$, grain size decreases. As dielectric constant of BT strongly depends on the grain size or particle size, for sample-3 dielectric constant decreased drastically as grain size reduced to $2.113 \mu \mathrm{m}$ and $1.538 \mu \mathrm{m}$ for sample-4. Origin of the decrease of dielectric constant was attributed to the reduction of tetragonality with the decrease in particle size ${ }^{(12)}$. Hence it is expected that particle size is very important parameter in selection of powder to get high dielectric constant.

The variation of the dielectric constant with frequency (Fig. 4) at room temperature for the pure (sample-1) and Zr doped BT. In all investigated samples dielectric constant initially have large value at low frequency and was found to attain more or less constant at lower frequency region (0 to $9 \mathrm{MHz}$ ) and then dielectric constant decreases with frequency. Dielectric constant also decrease as the wt\% of $\mathrm{ZrO}_{2}$ increases in BT. P. Sarah 
and Suryanarayana also found that dielectric constant decrease as the vol. \% of BT decreases, that is doping in the BT is increased ${ }^{(13)}$.

(iv). Frequency Dependence of Dielectric Loss Tangent: The high dielectric permittivity combined with low dissipation factor makes Zr doped BT ceramics one of the promising candidates for dynamic random access memory, decoupling capacitors, and dielectric field tunable elements for high frequency device applications ${ }^{(3)}$.

The dielectric losses were a combined result of electrical conduction and orientational polarization of the matter. The energy losses, which occur in dielectrics, were due to dc conductivity and dipole relaxation. The loss factor $(\tan \delta)$ of a dielectric material is a useful indicator of the energy loss as heat.

Variation of $\tan \delta$ as a function of Zirconium percentage is shown in Fig. 5. Loss tangent obeys a decreasing tendency with increasing Zirconium percentage. In high frequency range dissipation factor does not depend on frequency $(<20 \mathrm{MHz})$.

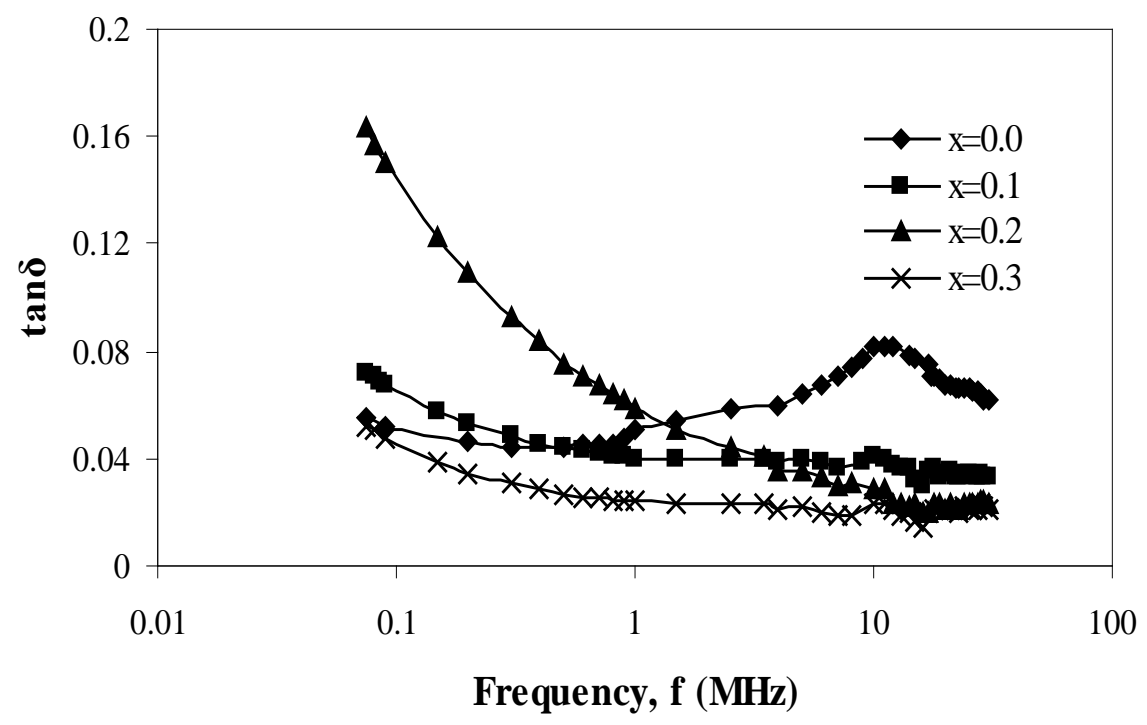

Fig. 5: Variation of $\tan \delta$ with frequency of $\mathrm{Ba}\left(\mathrm{Ti}_{1-\mathrm{x}} \mathrm{Zr}_{\mathrm{x}}\right) \mathrm{O}_{3}$, where $\mathrm{x}=0.0,0.1,0.2$ and 0.3 .

(v). Frequency Responsive Resistivity: The resistivity at room temperature in the frequency range $75 \mathrm{kHz}-30 \mathrm{MHz}$ shows that at higher frequency region the resistivity, $\rho$ of samples falls asymptotically to lower values. With the increase of $\mathrm{ZrO}_{2}$ the resistivity of the samples shows same characteristics up to $0.2 \mathrm{wt} \%$ addition but the value of the resistivity increased for further addition of $\mathrm{ZrO}_{2}$ in BT. Resistivity also can be said to depend on the grain size of the sample, as sample 4 having smaller grain size showed higher resistivity. 

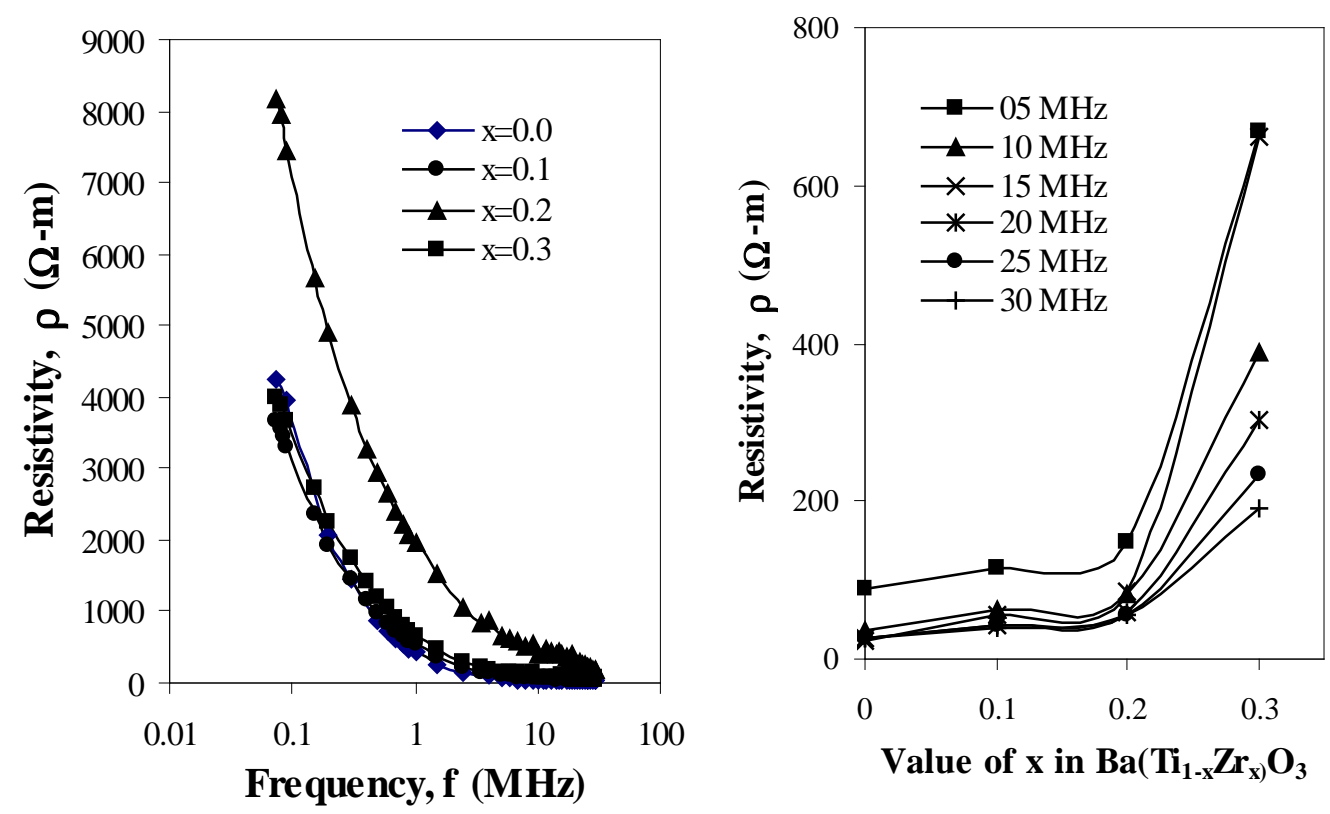

Fig. 6: Comparison of resistivity with (a) frequency and (b) $\mathrm{Zr}$ content of $\mathrm{Ba}\left(\mathrm{Ti}_{1-\mathrm{x}} \mathrm{Zr}_{\mathrm{x}}\right) \mathrm{O}_{3}$ (where $\mathrm{x}=0.0,0.1,0.2$ and 0.3 ).

It is considered that the ac conductivity is contributed by hopping of localized and free charges ${ }^{(14)}$. When $\mathrm{Zr}$ ion occupies Ba-sites, $\mathrm{Ti}^{4+}$ is reduced to $\mathrm{Ti}^{3+}$ and formed a conduction electron $\left(\mathrm{Ti}^{4+} \cdot \mathrm{e}\right)$ in order to keep charge neutrality. Subsequently, the resistivity of ceramic decreases sharply ${ }^{(15)}$.

\section{CONCLUSIONS}

Grain size of the BT ceramics with $5.18 \mathrm{wt} \% \mathrm{ZrO}_{2}$ addition was larger than that of pure BT. But with the increase of $\mathrm{ZrO}_{2}$ in $\mathrm{Ba}\left(\mathrm{Ti}_{1-\mathrm{x}} \mathrm{Zr}_{\mathrm{x}}\right) \mathrm{O}_{3}$, grain size of the samples decreased. Dielectric property of Zr doped BT ceramics was affected by dopant amount. SEM images of BT ceramics has shown small and coarse grain which was confirmed by EDAX Spectra.

Dielectric constant of pure BT bulk samples showed a maximum value of about 1000 when grain size was around $1.238 \mu \mathrm{m}$. After $5.18 \mathrm{wt} \% \mathrm{ZrO}_{2}$ doping, grain size of the grown materials increases. But with further increase of $\mathrm{ZrO}_{2}$ weight\% in $\mathrm{Ba}\left(\mathrm{Ti}_{1-\mathrm{x}} \mathrm{Zr}_{\mathrm{x}}\right) \mathrm{O}_{3}$, grain size decreases. Considering the investigation of Timothy R. Armstrong and Relva C. Buchanan ${ }^{(2)}$ we may conclude that it is the result for large un-doped core region existence and non-homogeneous distribution of additives on sample 2.

The loss factor of pure and doped BT showed different results. Pure BT showed relaxation after $11 \mathrm{MHz}$ but there was no significant relaxation found in doped samples. For the doped samples with the increase in frequency, loss factor decreased significantly and remain constant at higher frequency region $(>20 \mathrm{MHz})$.

The resistivity of BT ceramic was found to be high. As the frequency was increased, the resistivity of $\mathrm{Ba}\left(\mathrm{Ti}_{1-\mathrm{x}} \mathrm{Zr}_{\mathrm{x}}\right) \mathrm{O}_{3}$ showed asymptotic behavior. With the increase 
in $\mathrm{Zr}$ content the resistivity of the samples remain almost constant up to .2 wt\% addition and further increase in $\mathrm{Zr}$ increase the resistivity of the samples.

\section{REFERENCES}

1. H. R. RUKMINI, R. N. P. CHOUDHARY AND V. V. RAO, Structural and Dielectric Properties of $\mathrm{Pb}_{0.91}(\mathrm{La}, \mathrm{K})_{0.09}\left(\mathrm{Zr}_{0.65} \mathrm{Ti}_{0.35}\right)_{0.9775} \mathrm{O}_{3}$ Ceramics, J. Mat. Sci, 34 (1999) 4815 4819.

2. TIMOTHY R. ARMSTRONG, RELVA C. BUCHANAN, Influence of Core-Shell grains on the internal stress state and permittivity response of Zirconia-modified Barium Titanate, $J$. Am. Ceram. Soc. 73(5), 1990.

3. VESNA PAUNOVIC, LJILJANA ŽIVKOVIC, LJUBOMIR VRACAR, VOJISLAV MITIC, MIROSLAV MILJKOVIC, The Effects of Additive on Microstructure and Electrical Properties of $\mathrm{BaTiO}_{3}$ Ceramics, Serbian J. Elect. Eng. 1 (3), 89-98, 2004.

4. Y. M. CHIANG, D. BIMIE AND W. D. KINGERY, Physical Ceramics-Principles for Ceramic Science and Engineering, John Wiley \& Sons, New York, 1997.

5. H. T. MARTIRENA AND J. C. BURFOOT, Grain-Size Effect on Properties of Some Ferroelectric Ceramics, J. Phys. C., 7, 3182-92, 1974.

6. R. N. DAS AND P. PRAMANIK, Chemical Synthesis of Nanocrystalline $\mathrm{BaTiO}_{3}$ and $\mathrm{Ba}_{1-\mathrm{x}} \mathrm{Sr}_{\mathrm{x}} \mathrm{Ti}_{1-\mathrm{y}} \mathrm{Zr}_{\mathrm{y}} \mathrm{O}_{3}$, Nanotechnology, 15, 279-282, 2004.

7. JIN HYUN HWANG AND YOUNG HO HAN, Electrical Properties of Cerium-Doped $\mathrm{BaTiO}_{3}$, J. Am. Ceram. Soc., 84(8), 1750-1754, 2001.

8. S. K. ROUT, T. BADAPANDA, E. SINHA, S. PANIGRAHI, P. K. BARHAI AND T. P. SINHA, Dielectric and phase transition of $\mathrm{BaTi}_{0.6} \mathrm{Zr}_{0.4} \mathrm{O}_{3}$ ceramics prepared by a soft chemical route, Appl. Phys. A, 91, 101-106, 2008.

9. N. ABDELMOULA, H. CHAABANE, H. KHEMAKHEM, R. VON DER MÜHLL AND A. SIMON, Relaxor or classical ferroelectric behavior in A site substituted perovskite type $\mathrm{Ba}_{1-\mathrm{x}}\left(\mathrm{Sm}_{0.5} \mathrm{Na}_{0.5}\right)_{\mathrm{x}} \mathrm{TiO}_{3}$, Phys. Stat. Sol. (A),203(5), 987-996, 2006.

10. TIMOTHY R. ARMSTRONG, LAURIE E. MORGENS, ALENA K. MAURICE AND RELVA C. BUCHANAN, Effects of Zirconia on Microstructure and dielectric properties of Barium Titanate, Ceramics. J. Am. Ceram. Soc. 72 (4), 605-611, 1989.

11. M. APARNA, T. BHIMASANKARAM, S. V. SURYANARAYANA, G. PRASAD AND G. S. KUMAR, Effect of Lanthanum Doping on Electrical and Electromechanical Properties of $\mathrm{Ba}_{1-\mathrm{x}} \mathrm{La}_{\mathrm{x}} \mathrm{TiO}_{3}$, Bull. Mater. Sci. 24(5), 497-504, 2001.

12. KYUNG-WOOK PAIK, JIN-GUL HYUN, SANGYONG LEE AND KYUNG-WOON JANGNANO, Epoxy/BaTiO ${ }_{3}\left(\mathrm{SrTiO}_{3}\right)$ Composite Films and Pastes for High Dielectric Constant and Low Tolerance Embedded Capacitors in Organic Substrates, IEEE, Electr. Systemint. Tech. Conf. 2, 94-801, 2006.

13. SARAH AND S. V. SURYANARAYANA, Dielectric properties of piezoelectric 3-0 composites of lithium ferrite/barium titanate, Bull. Mater. Sci. 26(7), 745-747, 2003.

14. SHRABANEE SEN AND R. N. P. CHOUDHARY, Structural, Dielectric and Electrical Properties of Ca Modified $\mathrm{BaSn}_{0.15} \mathrm{Ti}_{0.85} \mathrm{O}_{3}$ Ceramics, J. Mat. Sci. 40, 5457-5462, 2005.

15. Y. PU, W. CHEN, S. CHEN, HANS T. LANGHAMMER, Microstructure and dielectric properties of dysprosium-doped barium titanate ceramics, Cerâmica, 51, 214-218, 2005.

Journal of Bangladesh Academy of Sciences, Vol. 32, No. 2, 221-229, 2008 